\title{
Sociedad civil y participación ciudadana
}

\author{
Ochman, Marta*
}

\section{Resumen}

Las teorías recientes de la gobernanza consideran la participación ciudadana como elemento indispensable para un buen gobierno. Sin embargo, pocos estudios todavía se centran en la calidad y eficiencia de ésta, al mismo tiempo que no faltan pruebas del efecto desestabilizador que la sociedad civil puede tener sobre el gobierno. El objetivo de este trabajo es proponer una delimitación teórica entre el concepto de ciudadanía y de sociedad civil. Dada la complejidad del tema, el análisis retoma los núcleos semánticos de ambos conceptos, sin considerar todos los significados acumulados a través de la evolución histórica de los campos de estudio. La metodología consistió en el análisis en documentos que permitieron reflexionar sobre los espacios teóricos compartidos/exclusivos de estos conceptos-, este trabajo se limita a dos ejes: Ios derechos y la participación. Se retoman las conceptualizaciones de la ciudadanía que aspiran a incorporar el pluralismo como parte constitutiva del concepto, al mismo tiempo que enfatizan la dimensión de participación sobre el disfrute de derechos, principalmente las reflexiones de Jürgen Habermas sobre la opinión pública y la propuesta de la ciudadanía plural de Michael Walter. Se concluye que es necesario el uso más restringido de estos conceptos, dado que homologarlos no ofrece solución real a los problemas que inspiraron el acercamiento teórico, y particularmente, no logran revitalizar la ciudadanía activa como la capacidad de influir sobre el sistema político y el proceso de conformación del marco legal vigente.

Palabras clave: Ciudadanía, sociedad civil, participación ciudadana, Estado.

\section{Civic Society and Citizen Participation}

Recent governance theories consider citizen participation as an indispensable element for good government. However, few studies have centered on the quality and efficiency of this aspect, and at the same time there is evidence of the destabilizing effect that civic society has

Recibido: 03-11-24. Aceptado: 04-08-19

Profesora investigadora en el Departamento de Estudios Sociales y Relaciones Internacionales del Instituto Tecnológico y de Estudios Superiores de Monterrey, Campus Estado de México. Carrera. A Lago de Guadalupe, s/n, Atizapán de Zaragoza, Estado de México.

E-mail:mochman@itesm.mx 
on government. The objective of this study is to propose a delimitation theory between the concept of citizenship and that of civic society. Given the complexity of the topic, the analysis studies the semantic nucleus of both concepts, without considering all of the significances accumulated over the historic evolution of this field of study. The methodology consisted of an analysis of documents that permited a reflection of the theoretical spaces that are shared and/or exclusive to each concept; this paper limited itself to two tangents: rights and participation. The conceptualization of citizenship was restudied with the hope of incorporating pluralism as a constituent part of the concept, and at the same time the dimension of participation is emphasized in relation to freedom of rights, principally those related to the reflections of Jurtgen Habermas on public opinion and the proposal of citizenship on the part of Michael Walter. The conclusion is that it is necessary to employ a more restricted use of these concepts, given that equal status for both elements does not offer a real solution to the problems that stimulated the initial approach to political systems and processes of conformation in the present legal framework.

Key words: Citizenship, civic society, citizen participation, state.

\section{Introducción}

Las teorías recientes de la gobernanza -como respuesta al sentimiento de crisis permanente y creciente riesgo de ingobernabilidad- consideran la participación ciudadana como elemento indispensable para un buen gobierno. Sin embargo, pocos estudios todavía se centran en la calidad y eficiencia de ésta, al mismo tiempo que no faltan pruebas del efecto desestabilizador que la sociedad civil puede tener sobre el gobierno. El objetivo de esta reflexión es defender la necesidad de una mayor delimitación teórica entre el concepto de ciudadanía y el de la sociedad civil.

Desde que Alexis de Tocqueville en La democracia en América presentó las organizaciones intermedias como el recurso más eficiente en contra del despotismo benigno de las sociedades democráticas, la frontera teórica entre la sociedad civil y la ciudadanía se traza tenue y ambigua. En la teoría moderna, desde el planteamiento de Marshall en la década de los cincuenta se plantea el papel de los movimientos socia- les como factor que contribuyó a la ampliación de los derechos ciudadanos, al mismo tiempo que el discurso de la ciudadanía legitima y facilita la aparición de nuevos movimientos sociales, como "agentes creativos de nuevos derechos" (Zapata-Barrero, 2001: 43).

Esta postura es retomada, por ejemplo, por Held (1997: 53), quien afirma que la evolución de la ciudadanía está estrechamente vinculada con los movimientos sociales, tanto los tradicionales que reflejaban la lucha de clases en el capitalismo, como los nuevos que luchan por conquistar o ampliar el grado de autonomía y control sobre la vida de los individuos.

La teoría política reconoce, entonces, la relación entre la ciudadanía y la sociedad civil, y el renacimiento del interés teórico y práctico por estos conceptos a mediados de los años ochenta se inscribe en un mismo contexto: la preocupación por la atrofia del espacio público, limitado por el Estado burocrático y por el mercado agresivo. La despolitización de las sociedades democráticas se traduce en la desconfianza frente a los políticos, 
baja participación electoral, y en general el repliegue de los individuos hacia la esfera privada.

Por otro lado, la transición a la democracia en los países de Europa Central y del Este, así como de América Latina se empantana en el proceso de una consolidación inacabada, incapaz de romper las viejas estructuras del clientelismo y paternalismo. La necesidad de expandir las prácticas democráticas y de fortalecer la cultura ciudadana más allá de un simple estatus formal, reintroducen el concepto de la ciudadanía y en muchos casos los asimilan al discurso de la sociedad civil. En este sentido, tanto los debates sobre la ciudadanía, como los de la sociedad civil son respuesta a la privatización de la vida política, que implica la existencia de consumidores y de expertos, pero la exclusión de individuos reales o su conceptualización como individuos egoístas, competidores por bienes escasos, indiferentes frente a las necesidades y demandas de los demás (Young, 1995).

En este contexto, la teoría de la ciudadanía y la teoría de la sociedad civil se han presentado como herramientas útiles para conceptualizar los reclamos de la inclusión, del reconocimiento social y de la redistribución económica. Para muchos autores (Isin y Turner (2002), Touraine (1999), Habermas (1996), Young (1995) son los fenómenos vinculados con la postmodernidad -la fragmentación y el pluralismo de identidades, la crisis del Estado nacional y la aparición de los nuevos movimientos sociales- los que justifican la necesidad de una redefinición teórica de la ciudadanía. Para otros, la ciudadanía se vuelve un concepto anticuado e inadecuado para describir y explicar los nuevos fenómenos sociales, que por ende debe ser reemplazado por categorías nuevas, como la de sociedad civil entendida como la capacidad de acción colectiva.

Como mencionan Kymlicka y Norman (1997) o Janoski y Gran (2002) en sus revisiones de la teoría de la ciudadanía, para algunos autores la ciudadanía no es más que un concepto de carácter discriminatorio, concebido desde un modelo particular y dominante de una sociedad histórica, que pretende imponer la identidad de un varón blanco de clase media a la multiplicidad de las identidades reales, que nunca desaparecerán ni podrán disolverse en un ideal de la ciudadanía universal. Estos autores subrayan que el proceso de la construcción de la ciudadanía fue, y sigue siendo, un proceso de exclusiones externas (construidas en torno a la nación) pero también internas (construidas en torno al género, clase o etnia). En este sentido, la construcción de la nacionalidad a través de la extensión de los derechos ciudadanos, como lo plantea Marshall, no es más que un mito (Marx, 2002).

¿Es, entonces, la ciudadanía un sinónimo de la sociedad civil? ¿Es un concepto ya anticuado, que describe una relación pasada del individuo moderno con un Estado moderno? ¿O es todavía un concepto necesario, una categoría teórica que permite comprender mejor la realidad social y política actual? Este análisis comparte el diagnóstico de Zolo (1997: 122) de la inflación normativa de la ciudadanía y lo extiende al concepto de la sociedad civil. Ambos conceptos se han convertido en un marco teórico de "todos los reclamos normativos surgidos en Oc- 
cidente en este siglo", fenómeno que provoca el riesgo de diluir su importancia histórica y funcional.

\section{Desarrollo}

La homologación del uso de los conceptos de la sociedad civil y la ciudadanía ha afectado sobre todo éste último, que tiende a definirse como un concepto marco, vacío de un sentido adscrito, que cada quien llena con los sentidos que quiere (Shuck, 2002) por su irradicable vaguedad del significado (Miller, 1997), concepto que moldeamos de acuerdo con nuestras preferencias (Dahrendorf, 1997) y que refleja las luchas acerca de quién decidirá cuáles son los problemas comunes y cómo abordarlos (Sojo, 2002). Por otro lado, la sociedad civil se desliga de la utopía autolimitada (Arato y Cohen, 1999) y se presenta como el sustituto ideal para el Estado opresor, o por lo menos como un actor capaz de sustituir la racionalidad estratégica del Estado por la racionalidad comunicativa de la sociedad civil.

Sin embargo, un concepto teórico no puede ampliarse indefinidamente y el uso homologado de los referidos términos amenaza con privarnos de una herramienta teórica valiosa para entender si y cómo pueden los individuos influir en la lógica del proceso político. La propuesta de una delimitación teórica entre estos conceptos se construye aquí en dos pa- sos: primero, analizamos las coincidencias y las divergencias en la definición teórica de los conceptos, y después revisaremos los modelos de Walzer y de Habermas de la interacción entre los individuos, la sociedad y el Estado.

\subsection{Las indefiniciones conceptuales}

Sin negar la imposibilidad de subsumir las diversas definiciones de ciudadanía en una sola definición, podemos afirmar que la ciudadanía sí posee un núcleo conceptual, que constituye un punto de partida para las distintas interpretaciones, sean éstas republicana, liberal, comunitarista o pluralista ${ }^{1}$. Este núcleo está constituido por dos conceptos complementarios: estatus y práctica. El estatus (ciudadanía pasiva) se refiere a la posición que la persona ostenta frente al Estado, con su respaldo y consentimiento, como poseedora de derechos y miembro de una comunidad determinada (distinta de otras comunidades). El estatus del ciudadano le da la garantía de protección legal y política de un poder coercitivo, al mismo tiempo que implica obligación de proteger la comunidad política que le otorga este estatus. La obligación de proteger el sistema político no se refiere necesariamente a la protección contra amenazas externas, sino a la obligación de pensar y actuar con el ideal del bien común, de defender y mejorar las institucio-

1 Se retoman aquí las definiciones de Zapata-Barrero (2001); Isin y Turner (2002); Opazo (2000); Touraine (1999); Zolo (1997); Lehning (1997), Janoski y Gran (2002), Davidson (2000), Habermas (1998) y Soltan (1999). 
nes políticas, y esta obligación se realiza a través de la ciudadanía como práctica (ciudadanía activa).

La práctica (ciudadanía activa) implica el poder y la capacidad de formular las leyes bajo las cuales se está viviendo, que a su vez postula la posibilidad y la capacidad de participar en los debates sobre el bien común. Como práctica, la ciudadanía necesariamente exige un régimen democrático y un conjunto de competencias cívicas (identidad, cooperación, tolerancia, limitación del interés egoísta, respeto a las reglas como la de la mayoría, por mencionar algunos). La identidad compartida es la que permite desarrollar el resto de las competencias cívicas, incluyendo el saber cómo participar con éxito en el proceso del gobierno (Soltan, 1999: 2).

Por su parte, y de acuerdo con la definición de Arato y Cohen (1999: 118), la sociedad civil son las "asociaciones y públicos, estabilizados por los derechos fundamentales (de asociación, reunión, expresión, prensa y privacidad) que operan de acuerdo con una lógica normativa de coordinación de la acción comunicativa". Los autores destacan tres características fundamentales: su pluralismo, su autolimitación frente al mundo sistémico (el Estado y la economía) y su estructura dual: la sociedad civil institucionalizada por un lado, y las redes, solidaridades y relaciones sociales por el otro.

Ambos conceptos describen, entonces, una relación entre los individuos y las instituciones, donde, idealmente, los individuos de forma activa influyen en la actuación y el diseño de las instituciones. Pero mientras el concepto de la ciudadanía describe principalmente una relación vertical entre una persona y las instituciones estatales (Zapata-Barrero, 2001), la sociedad civil enfatiza las relaciones horizontales entre los ciudadanos, en el marco del espacio público.

En palabras de Zapata-Barrero (2001: 48), "la ciudadanía es una identidad y una práctica autorizada y legalmente reconocida que permite a la persona actuar públicamente, frente a otras identidades que también son personales pero no autorizadas públicamente desde las instancias estatales. La ciudadanía es, pues, la identidad que debe manifestar la persona cuando se relaciona con las instituciones estatales, y es la única que las instituciones estatales reconocen como legalmente válida para relacionarse con las personas. Por esta razón, siempre que se hable de ciudadanía deberá uno situarse en la confluencia de la relación entre la persona y el Estado".

También para Zolo (1997:123) la ciudadanía moderna -ligada al proceso de la diferenciación funcional de la sociedad- formaliza el proceso de abstraer a los individuos de las determinaciones propias de otros subsistemas, e implica necesariamente la existencia de un individuo, no un grupo.

La sociedad civil, en cambio, no existe si se elimina la pluralidad de identidades, incluyendo las no reconocidas por el Estado, las públicamente no existentes, ignoradas 0 incluso desautorizadas por el Estado. Para Arato y Cohen, siguiendo a Habermas (1998), la sociedad civil por excelencia son las instituciones especializadas en la reproducción, cuestionamiento y modificación de tradiciones, solidaridades e identidades.

Frente a la atractiva pluralidad de la sociedad civil, la ciudadanía se presenta 
como una categoría unificadora y homogeneizante, que históricamente ha servido para establecer exclusiones hoy inaceptables. Pero incluso los defensores más entusiastas de la pluralidad en la vida social y política reconocen la necesidad de un ámbito donde los actores plurales sean capaces de escucharse mutuamente y comprometerse a buscar un compromiso político, aunque fuera temporal. Aquí es donde la distinción entre la sociedad civil y la ciudadanía cobra importancia teórica. Como miembro de las asociaciones o públicos particulares, el individuo crea y defiende su identidad, formula y presenta los reclamos de reconocimiento o retribución. Aquí actúa como miembro de una familia concreta, una iglesia, una colonia. Como ciudadano, se le exige la antigua virtud republicana de trascender las identidades particulares de la familia, religión o grupos pequeños, en aras del bien común, un ideal irrealizable, pero útil en el proceso de la búsqueda de compromisos.

Esta afirmación no pretende establecer una diferencia radical entre un individuo autónomo como ciudadano y un individuo comunitarista en el caso de la sociedad civil. De hecho, ambos conceptos surgen en el mismo contexto histórico: la crisis del orden feudal y el surgimiento del Estado moderno. En este sentido, ambos presuponen la existencia de individuos autónomos, poseedores de derechos inherentes, y del disenso normativo sobre la conceptualización de la vida buena, que marca la disolución de las comunidades orgánicas. Frente a la conceptualización comunitarista que le niega al individuo el derecho y la necesidad de cuestionar y redefinir la tradición, el surgimiento de la sociedad civil es solamente posible cuando surgen las identidades racionales y solidarias, así como los actores autónomos con la capacidad de interpretar y dar significación nueva a la tradición (Arato y Cohen, 1999: 89-90).

Sin embargo, aunque ambos son individuos autónomos y poseedores de derechos, el concepto de ciudadanía se refiere a un rol específico: se es ciudadano cuando se procura traducir las demandas de reconocimiento -frecuentemente fundamentadas con el discurso de derechos inherentes- en regulaciones legales vigentes.

El problema de los derechos constituye, entonces, otro de los ámbitos de la diferencia entre sendos conceptos. Como hemos visto, la ciudadanía se define como el disfrute de los derechos legales, que protegen a los individuos frente a cualquier poder coercitivo, sea éste del Estado, del sistema económico o de los otros miembros de la comunidad. También Arato y Cohen (1999: 88) enfatizan que las instituciones de la sociedad civil solamente pueden estabilizarse sobre la base de los derechos, que clasifican en tres conjuntos: los concernientes a la reproducción cultural (libertad de pensamiento, de prensa, de expresión, de comunicación); los que aseguran la integración social (libertad de asociación, de reunión), y los que aseguran la socialización (protección de la privacidad, intimidad e inviolabilidad de la persona).

Sin embargo, desde la perspectiva de la teoría de la sociedad civil, el Estado no es fuente ni de los derechos ni de su legitimidad. En palabras de los mismos autores (1999: 88), "si bien el Estado es el agente de la legalización de los derechos, no es ni la fuente ni la base de su validez. 
Los derechos surgen como demandas reivindicadas por grupos e individuos en los espacios públicos de una sociedad civil emergente. Pueden garantizarse por la ley positiva pero no son equivalentes a la ley ni derivados de ella; en el campo de los derechos, la ley asegura y estabiliza lo que se ha conseguido de manera autónoma por los actores sociales en la sociedad".

La teoría de la ciudadanía comparte con la sociedad civil el discurso de los derechos humanos a nivel normativo, pero enfatiza el hecho de que los derechos ciudadanos son protegidos y defendidos por la ley vigente, a diferencia de la abstracción de los derechos humanos. Solamente los derechos ciudadanos son legales y políticos, en el sentido de legislados por cuerpos instituidos y encargados de tomar decisiones, y promulgados y defendidos por el poder ejecutivo y judicial (Janoski y Gran, 2002). La teoría sistémica también enfatiza esta interpretación de los derechos. La ciudadanía opera dentro de la esfera soberana del Estado moderno; es decir, dentro de una organización política territorial y burocrática. La teoría del derecho natural ve los derechos de ciudadanía como derechos naturales y universales que los hombres poseen en tanto miembros de una comunidad política.

En la práctica, la protección legal formal y los beneficios asociados con la ciudadanía son regulados por el código político moderno, un código funcional que depende de los requerimientos de "seguridad" y "regulación del miedo". Esto limita los derechos universales por medio de subordinación y de exclusión. En principio sólo los miembros de una comunidad política na- cional son ciudadanos, en oposición a los "extranjeros" (Zolo, 1997: 124).

Cuando se habla de la universalidad de los derechos ciudadanos, no se implica su aplicabilidad a la humanidad como tal, éstos son universales en el sentido de aplicables a todos los miembros de la comunidad política concreta. Y para muchos autores, este principio de universalidad significa que los derechos particulares no pueden ser aceptados por el Estado como derechos ciudadanos, porque como tales conllevarían la demanda de ser extendidos a todos los ciudadanos. Por ende, la ciudadanía implica una igualdad formal (no perfecta), procedimental, en el sentido de que constituye el fundamento para reclamar el goce de derechos efectivos (Janoski y Gran, 2002).

Esta dificultad de introducir dentro de la ciudadanía los derechos diferenciados es, indudablemente, el contrapeso de la ventaja de la protección legal. Históricamente, la ciudadanía se formó como la exigencia de la igualdad formal, en oposición a los derechos diferenciados de las sociedades pre-modernas, y en esta exigencia de la igualdad consistió el poder emancipatorio de la ciudadanía. Durante los primeros siglos de la existencia de la ciudadanía moderna, el énfasis estaba en la inclusión de los grupos marginados (mujeres, minorías étnicas o clase obrera) dentro de la ciudadanía moderna. El debate postmoderno se centra en la insuficiencia de la igualdad formal para los grupos marginados y con identidades que nunca se asimilarán a la identidad abstracta del ciudadano.

Para los autores que defienden el concepto de la ciudadanía diferenciada en función del grupo de Iris Marion Young 
(1995), la defensa de la ciudadanía como expresión de un espacio público homogéneo es imposible en un mundo postmoderno, caracterizado por la afirmación de la diferencia y por la existencia de desigualdades entre grupos. Para estos autores, un espacio público justo debe estar compuesto no sólo por individuos iguales, sino también por grupos diferentes, que además gozarán de la aplicación diferenciada de las leyes como condición de posibilidad de la participación en lo público. Como hemos visto, para la ciudadanía es esencial la participación directa del individuo, sin la mediación del grupo.

El planteamiento inicialmente radical de Young, se desarrolla matizado por las afirmaciones sobre las características necesarias de los grupos (grupos sociales vs. grupos agregativos) y de las identidades (relacionales no esenciales, abiertos no exclusivos), que buscan reafirmar la esencia de la ciudadanía como la búsqueda del bien común, de la justicia más allá de los intereses particulares de los grupos. Incluso los críticos más consistentes de los límites de una ciudadanía abstracta, como las feministas, reconocen la necesidad de un ámbito donde los reclamos se negocian en aras de traducirlos en políticas, ámbito que exige actitudes diferentes a las que manifestamos como miembros de grupos pequeños, con identidades y necesidades definidas.

En palabras de Anne Phillips (1993: 86) "ser una buena ciudadana no es lo mismo que ser una buena madre, no es lo mismo que ser una buena feminista, no es lo mismo que ser una buena vecina. Existe un salto cualitativo entre la forma en que nos relacionamos con otros en los grupos más privados e informales y las relaciones necesarias en una interacción política." La sociedad civil como el marco de los grupos plurales no necesita preocuparse por la unidad social o el problema de la gobernabilidad en el contexto de la sociedad fragmentada. Sería ilógico demandar una perspectiva general cuando se construye identidades y reclama derechos. La ciudadanía, en cambio, evoca la idea republicana de deber, incluso de sacrificio, sobre todo del interés particular, del estatus particular, en el nombre del bien común. La ciudadanía exige establecer un equilibrio entre los derechos y las obligaciones, e incluso sin adoptar la postura extrema de los neoconservadores o comunitaristas sobre la importancia de las obligaciones, debemos reconocer que si votar es un derecho, también es la obligación que, hoy en día, algunos Estados deben imponer a sus ciudadanos para evitar el ausentismo. Si la simple movilización del consenso es muy fácil en la sociedad actual, la movilización para la acción es cada vez más difícil (Von Beyme, 1994: 284).

Resumiendo entonces las líneas divisorias entre el concepto de la ciudadanía y de la sociedad civil, el primero se refiere a la relación vertical entre el individuo y el Estado, cuyo objetivo es lograr que la legislación vigente refleje sus demandas y sus necesidades. La sociedad civil, en contraste, es el marco de las múltiples relaciones horizontales, cuyo fin consiste en construir identidades y definir las necesidades que éstas implican, sin necesariamente exigir que se traduzcan en las políticas públicas. El concepto de la ciudadanía es útil para analizar las relaciones entre el Estado y el individuo, mientras que el estudio de las relaciones 
horizontales entre los individuos y los grupos infla innecesariamente el concepto y lo asimila al discurso de la sociedad civil.

Muchos autores retoman esta distinción ${ }^{2}$, sin embargo tienden a asimilar el ámbito de la sociedad civil al concepto de ciudadanía, construyendo de forma más o menos explícita la teoría de la ciudadanía a dos niveles. Detrás de estos acercamientos teóricos están, principalmente, dos intenciones: revitalizar el concepto de la ciudadanía y revalorar su componente activo, o explicar cómo la sociedad civil puede efectivamente influir sobre la lógica del Estado, en un mundo cada vez más diferenciado.

Revisaremos aquí dos de estas teorías, para hacer evidente el trato distinto que se le da al problema, pero también para señalar que la asimilación de la teoría de la sociedad civil dentro de la teoría de la ciudadanía no resuelve ninguno de los problemas que se quiere solucionar.

\subsection{La ciudadanía plural de Michael Walzer}

Michael Walter (1970 y 1995) representa un intento de sintetizar corrientes distintas, y en algunos contextos opuestos, de la teoría política, incorporando a su perspectiva comunitarista la preocupación republicana por la privatización excesiva de la sociedad, y el discurso liberal de la justicia. Específicamente para su teoría de la ciudadanía plural (pluralist citizenship) Walzer rechaza la conceptualización liberal del ciuda- dano como sujeto de derechos que lo protegen contra el poder arbitrario, al mismo tiempo que lo alienan de la participación en la vida política. Aunque en sus orígenes basada en el principio del consentimiento, la teoría liberal de la ciudadanía, según Walzer, fue rebasada por la realidad moderna donde el gobierno se legitima simplemente por la ausencia de una oposición activa y expresa. Este tipo de compromiso no es suficiente para crear un sentimiento de lealtad y obligación de los ciudadanos para con el Estado.

Por su parte, el republicanismo clásico con su fórmula aristotélica de "mandar y ser mandado" difícilmente se puede realizar en una sociedad heterogénea y de organizaciones a gran escala, que minimizan el impacto individual sobre el proceso de la toma de decisiones.

Adicionalmente, Walter (1970: 218) retoma el problema muy importante para los comunitaristas de la exigencia republicana de trascender las identidades comunitarias formadas en el ámbito privado de la vida. El autor propone solucionar las contradicciones de las teorías clásicas aceptando que los lazos entre el individuo y el Estado no son directos, sino mediados por la participación en las organizaciones intermedias. Los ciudadanos se presentan ante el Estado no sólo como individuos, sino también como miembros de una variedad de otras organizaciones, con las cuales el Estado se debe relacionar para poder relacionarse con el individuo. En primera instancia, el ciudadano es un individuo que pertenece a la comu- 
nidad cívica amplia e inclusiva: el Estado. Éste protege no solamente sus derechos individuales y su privacidad, sino también su libre pertenencia a las asociaciones que él ha escogido. En la segunda dimensión, el ciudadano participa en el gobierno de los grupos intermedios, que a su vez influyen sobre la determinación de las políticas estatales. De esta forma, en las organizaciones intermedias, el individuo desarrolla los valores cívicos de compromiso, negociación y toma de decisiones, que adicionalmente le dan mayor seguridad en su relación con el Estado. Esta "doble membresía" permite también desarrollar el sentimiento de pertenencia y la aceptación voluntaria de las obligaciones que la vida en común exige, valores que sólo pueden ser desarrollados en las pequeñas sociedades, que son "moralmente superiores a las grandes" (Walter, 1970: 10). La obligación moral se extiende al Estado en la medida en que éste acepta y protege las asociaciones pequeñas.

Walter (1970: 224-225) resume así tres ventajas principales de la ciudadanía plural: a) una mayor seguridad del ciudadano frente al abuso o la negligencia de la burocracia estatal o frente a la opresión social; b) mayor responsabilidad del individuo frente a la comunidad; $y c$ ) la posibilidad de participar en el diseño de las políticas y la toma de decisiones.

Al mismo tiempo, aunque de manera más escueta, Walter (1995: 169-170) señala el problema que implica esta conceptualización si los grupos intermedios presentan reclamos en contra del Estado, y el ciudadano enfrenta el problema de la lealtad dividida. De hecho, como condición de posibilidad, Walzer plantea que el
Estado debe ser considerado como prioritario frente a las demás asociaciones particulares, y la lealtad hacia el Estado debe anteponerse a las demás pertenencias, porque el Estado es quien hace posible la existencia de los demás grupos, define las reglas de convivencia entre ellos, asigna recursos, pero sobre todo porque hace posible trascender la fragmentación y pensar el bien común. Walter (1970: 20) reconoce que el Estado puede convivir con las asociaciones que tienen reclamos parciales, pero no con las que postulan la primacía sobre la lealtad hacia el Estado. El afirmar la primacía del Estado sobre las asociaciones particulares no resuelve la contradicción de su planteamiento de que la pertenencia a las comunidades pequeñas es la condición de la ciudadanía. Implícitamente reconoce que hay un salto cualitativo entre ser el miembro de un grupo, o incluso de varios grupos no-excluyentes, y ser ciudadano en una comunidad abstracta, que puede proveer varios bienes para sus miembros, pero en ningún caso el bien superior, que sí defienden los grupos pequeños. Si la lealtad hacia el Estado se basa sólo sobre la lógica de proveedor de un marco legal $y$, hasta cierto grado, de recursos, el miembro de una asociación particular no tiene más motivos de lealtad hacia el Estado que el individuo egoísta liberal, que soporta el Estado como garantía de su libre disfrute de la vida privada.

El planteamiento de Walzer no escapa, entonces, a la necesidad de reconocer que las relaciones entre el Estado y el individuo se rigen por la lógica diferente a las relaciones inter-individuales e intergrupales. La participación en algunos grupos puede fortalecer la identidad ciu- 
dadana y promover las competencias cívicas, pero indudablemente hay otras pertenencias que la debilitarán.

\subsection{La ciudadanía en el mundo sistémico}

Tanto el concepto de la ciudadanía como el de la sociedad civil son difícilmente asimilables a las teorías sistémicas y el problema se centra en el concepto del sistema autorreferencial. El sistema político, como un sistema autorreferencial, produce las decisiones políticas exclusivamente en referencia a sus propios elementos, en sintonía con sus propias operaciones. Aunque está acoplado estructuralmente al entorno, el sistema político no extrae los elementos políticos del entorno sino decide por sí mismo cuáles elementos ajenos al sistema incorporará a sus operaciones. Si al mismo tiempo entendemos a los ciudadanos como individuos organizados que pretenden influir sobre el sistema político y obligarlo a retomar sus demandas como universalmente válidas, estamos frente a una obvia imposibilidad teórica de la ciudadanía activa.

Por otra parte, la teoría de Luhmann analiza el funcionamiento de los sistemas y no de la acción social. La sociedad civil tradicionalmente se ha identificado con la acción social y la imposibilidad de defender su conformación como un sistema societal funcionalmente diferenciado la ha marginado, e incluso ex- cluido, de los análisis en el marco de la teoría de Luhmann. La afirmación fundamental en el sentido que la sociedad no son los individuos sino la comunicación, ha impuesto una barrera aparentemente infranqueable entre la teoría de sistemas y el concepto de la sociedad civil.

No es de extrañar entonces que es Jürgen Habermas y su análisis de la relación entre el mundo sistémico y el mundo de vida, el que ha inspirado tanto los debates acerca de la ciudadanía, como la teoría de la sociedad civil, incluyendo a la conceptualización de Arato y Cohen que aquí hemos retomado. Uno de los objetivos de estos trabajos es analizar los mecanismos a través de los cuales el mundo de vida no sólo es capaz de defenderse en contra de la colonización de sus contrapartes sistémicas, sino también de influir en su operación, a través del espacio de la opinión pública. En sus análisis sobre la opinión pública Habermas ${ }^{3}$ no establece ninguna reflexión sistematizada sobre la relación entre la ciudadanía y la sociedad civil, y su lectura deja un amplio margen de ambigüedad, que posibilita varias interpretaciones.

Por un lado, el uso de los términos "ciudadanos" y "ciudadanía" como referencia a los individuos concretos que están interactuando en el espacio público, establece una homologación entre este concepto y la sociedad civil, compuesta de "esas asociaciones, organizaciones y movimientos surgidos de formas más 0 menos espontánea que recogen la reso- 
nancia que las constelaciones de problemas de la sociedad encuentra en los ámbitos de la vida privada, la condensan y elevándose, por así decir, el volumen o voz, la transmite al espacio de la opinión pública-política" (Habermas, 1998: 447).

Por otro lado, la distinción entre el público general de ciudadanos y el núcleo institucional en el ámbito de la opinión pública, y por el otro lado los partidos políticos y parlamentos como parte del sistema político, dan pie a una interpretación mucho más restringida de la ciudadanía, otra vez, como un rol específico que algunos miembros de la sociedad civil asumen en contextos muy específicos. Analicemos con más detenimiento esta ambigüedad. En Facticidad $y$ validez (1998:445) Habermas afirma que el espacio público político es sustentado por un público que se recluta de la totalidad de los ciudadanos. En la pluralidad de voces de ese público resuena el eco de experiencias biográficas.

"Entre los ciudadanos como portadores del espacio público-político y los miembros de la sociedad se da una unión personal, porque estos últimos, en los papeles complementarios que son el trabajador y consumidor, el de asegurado y el de paciente, el de contribuyente y el de cliente de las burocracias estatales, el de alumno, el de turista, el de participante en el tráfico automovilístico, etc., están expuestos de forma especial a las exigencias y fallos específicos de los correspondientes sistemas funcionales. Tales experiencias empiezan siendo elaboradas privadamente, es decir, interpretadas en el horizonte de una biografía que queda tejida con las demás biografías en los contextos de mundos de la vida comu- nes. Los canales de comunicación del espacio de la opinión pública están conectados con los ámbitos de la vida privada, con las densas redes de comunicación en la familia y en el grupo de amigos, así como con los contactos no tan estrechos con los vecinos, los colegas de trabajo, los conocidos, etc., y ello de suerte que las estructuras espaciales de las interacciones simples se amplían y abstraen, pero no quedan destruidas. Así, la orientación al entendimiento intersubjetivo, predominante en la práctica comunicativa cotidiana, se mantiene también para una comunicación entre extraños, que se efectúa a grandes distancias en espacios de opinión pública complejamente ramificados" (Habermas, 1998: 446).

Habermas (1998) establece la diferencia entre los miembros de la sociedad y los ciudadanos por dos razones. Primero, porque como lo marca el fragmento citado, un individuo se transforma en ciudadano cuando abandona la esfera privada de la opinión (lugares comunes culturales, convicciones normativas, prejuicios y agravios colectivos, distintos valores) y entra en la esfera de la opinión pública razonada y reflexiva (Habermas, 1996), que "busca interpretaciones públicas para sus intereses sociales y para sus experiencias, ejerciendo así influencia sobre la formación institucionalizada de la opinión y la voluntad políticas" (Habermas, 1998: 447). En esta distinción entre el público acostumbrado al ejercicio de las libertades y los movimientos populistas de masa claramente encontramos los postulados de la ciudadanía activa.

El uso del concepto de la ciudadanía se justifica también porque el espacio público necesita una base social de indi- 
viduos con igualdad de derechos, sin barreras de clase ni estratificación social, en resumen el espacio público sólo existe si existe la ciudadanía como estatus.

Si queremos encontrar a los ciudadanos como los que son capaces de formular las leyes bajo las cuales van a vivir -y no sólo legitimarlas-, resulta que estos pobladores del espacio público son demasiado débiles frente al sistema político. Siguiendo la descripción del funcionamiento del espacio público de Habermas, podríamos argumentar que la ciudadanía se realiza sólo en los núcleos más institucionalizados.

Habermas (1998: 454-455) afirma que "en las sociedades complejas el espacio de la opinión pública constituye una estructura intermediaria que establece una mediación entre el sistema político, por un lado, y los sectores privados del mundo de la vida y los sistemas de acción funcionalmente especificados, por otro. Representa una red extraoridinariamente compleja que se ramifica espacialmente en una pluralidad de espacios internacionales, nacionales, regionales, municipales, subculturales, que se solapan unos con otros; que, en lo que a contenido se refiere, se estructura conforme a puntos de vista funcionales, centros de gravedad temáticos, ámbitos políticos, etc., en espacios públicos más o menos especializados, pero todavía accesibles a un público de legos (...); y que, en lo tocante a densidad de la comunicación, a complejidad de su organización y alcance, se diferencia en niveles, desde los niveles episódicos que representan el bar, el café, o los encuentros y conversaciones en la caIle, hasta el espacio público abstracto, creado por medios de comunicación, que forman los lectores, oyentes y espectado- res aislados y diseminados por todas partes, pasando por espacios públicos caracterizados por la presencia física de los participantes y espectadores, como pueden ser las representaciones teatrales, las reuniones de las asociaciones de padres de las escuelas, los conciertos de rock, las asambleas de los partidos y congresos eclesiásticos".

En este espacio complejo, Habermas distingue, además, entre la arena y la galería, entre los actores y los espectadores. Aunque en última instancia el éxito de los actores depende del apoyo de los espectadores y aunque potencialmente todos pueden ser actores, Habermas (1998: 452-456), destaca la presencia de actores que disponen de poder organizativo y de recursos (el capital social, el dinero, el saber, la organización), y que son los que verdaderamente enlazan el espacio de la opinión pública con el espacio donde se forma la voluntad política: el complejo parlamentario, institucionalizado en términos del Estado de derecho.

"En el espacio de la opinión pública se forma influencia y en él se lucha por ejercer influencia. En esa lucha no sólo entra en juego el influjo político ya adquirido y acumulado (por acreditados ocupantes de cargos públicos, por partidos políticos establecidos, o por grupos conocidos, como Greenpeace, Amnistía Internacional, etc.) sino también el prestigio de grupos de personas y también de expertos que han adquirido su influencia en espacios públicos más especializados (por ejemplo, la autoridad de eclesiásticos, la fama de literatos y artistas, la reputación de científicos, el renombre y relumbre de estrellas de deporte y el mundo del espectáculo, etc.). Pues en cuanto el es- 
pacio público se ha extendido más allá del espacio de las interacciones simples, se produce una diferenciación entre organizadores, oradores y oyentes, entre arena y galería, entre escenario y espacio de espectadores. Los papeles de actor que, con la complejidad organizativa y el alcance de los medios de comunicación, crecientemente se profesionalizan y multiplican, vienen dotados de oportunidades diferenciales de ejercer influencia. Pero el influjo político que los actores cobran a través de la comunicación pública ha de apoyarse en última instancia en la resonancia y, por cierto, en el asentamiento, de un público de legos igualitariamente compuesto. El público de los ciudadanos ha de ser convencido por contribuciones e intervenciones inteligibles que tengan interés para todos a propósito de temas que se perciban como relevantes. El público posee esta autoridad porque es constitutiva de la estructura interna del espacio de la opinión pública, en el que los actores pueden presentarse" (Habermas, 1998: 444).

Esta distinción está también presente en otros teóricos de la sociedad civil, que como Arato y Cohen o Sidney Tarrow $^{4}$ hacen distinción entre los públicos plurales y asociaciones, entre moviliza- ciones a gran escala y formas de organización institucionalizadas, que aseguran la continuidad y la permanencia; entre los movimientos sociales y la sociedad civil institucionalizada, con capacidad de llevar a cabo las tareas estratégicas de negociación y diseño de pactos con las élites incluso cuando la movilización social ya se ha apagado.

\section{Conclusiones}

El problema de la interrelación entre los conceptos de ciudadanía y de sociedad civil no es fácil de resolver. Ambas categorías son tan amplias que necesariamente implican posturas normativas en sus definiciones. Para el concepto de ciudadanía, homologarla con la sociedad civil le da una nueva vitalidad y potencial emancipador renovado: ya no tiene que ser una categoría abstracta que exige renunciar a las identidades constitutivas de culturas marginadas y asimilarse a un postulado culturalmente dominante. Para la sociedad civil, el discurso de la ciudadanía permite marcar una distancia clara frente a los movimientos fundamentalistas o populistas, frente a los reclamos de institucionalizar los privilegios y los intereses privados. Este distanciamiento permite postular una sociedad no sólo civil,

Tarrow (1998) utiliza el concepto de ciclos de protesta, que establece una diferenciación entre el poder de desencadenar una acción social y la capacidad de controlarla o mantenerla activa. De la misma forma que Arato y Cohen, Tarrow considera que los movimientos no nacen solamente porque existan demandas o agravios ampliamente compartidos, sino porque incluso los pequeños grupos con poder organizativo aprovechan las oportunidades políticas para acelerar un proceso de difusión y de contagio. Las movilizaciones masivas forman el trasfondo de legitimación para las élites que formulan peticiones al gobierno, que éste puede satisfacer o reprimir. El autor subraya que es más fácil convocar a la acción que traducir las demandas en un juego político de negociación con el gobierno. Por ello, en gran parte el éxito de los movimientos sociales depende más de la capacidad organizativa que del tamaño de la movilización (Tarrow, 1998: 141-160). 
sino también cívica, en el sentido de asumir como propio el postulado de apertura hacia otros puntos de vista y de aceptación de las reglas de un juego político democrático.

Identificar esto conceptos no ofrece solución real a los problemas que inspiraron el acercamiento teórico, y particularmente no logra revitalizar la ciudadanía activa como la capacidad de influir sobre el sistema político y el proceso de conformación del marco legal vigente. Por el contrario, produce la ilusión que la simple participación en el espacio de la opinión pública nos convierte en ciudadanos activos. Remarco otra vez la afirmación que Klaus von Beyme retoma de Klandermans: en el mundo actual es extremadamente fácil movilizar el consenso y cada vez más difícil movilizar hacia la acción. La movilización cognitiva nos da la comodidad intelectual de defender las causas justas, cuando en realidad siguen siendo las élites especializadas, las que se encargan de seleccionar, organizar y negociar los temas y las demandas frente al Estado. La mayoría, ocupamos las gradas de los espectadores, en realidad aburridos, cansados o indiferentes frente a la multiplicidad de actuaciones, que nos llaman atención sólo cuando son envueltos en un contexto atractivo.

La recuperación de un significado mucho más restringido de la ciudadanía es también necesaria por su potencial integrador, que puede producir exclusiones, pero también crea solidaridades muy concretas, que han hecho posible, por ejemplo, la formación del Estado de bienestar en Europa. La comodidad de la movilización cognitiva nos lleva a apoyar muchas causas lejanas, más seguras en el sentido de que, desde México, defender la vida de una mujer en Nigeria no nos exigirá más acción que firmar una carta de protesta, mientras que defender la vida de una mujer en Juárez nos puede presentar exigencias de involucramiento mayor. Parafraseando a Oscar Wilde, las causas cercanas nos toman demasiadas tardes.

No se trata de postular aquí el regreso al ideal republicano de un ciudadano disciplinado y capaz de sacrificarlo todo en aras del supuesto bien común. El espacio plural nos permite transitar libremente entre diferentes identidades y luchar por el reconocimiento, sin necesariamente exigir regulaciones legales concretas. Pero también es cierto, que hoy en día es relativamente fácil obtener el reconocimiento, la declaración de que nuestra identidad y nuestra dignidad son valiosas para los demás, para la pluralidad. Es mucho más difícil lograr que el Estado traduzca el reconocimiento en derechos ciudadanos. Por ello, la ciudadanía sigue siendo necesaria, como una categoría que postula competencias y compromisos muy particulares, que nos hacen individuos capaces de construir una relación exigente frente al Estado.

La participación en las organizaciones intermedias, en los debates, en las múltiples asociaciones puede ayudar a desarrollar estas competencias, pero no debemos olvidar que sí existe un salto cualitativo entre ser el actor y el espectador en el espacio público. 


\section{Referencias Bibliográficas}

Aquín, Nora; Acevedo, Patricia y Rotonda, Gabriela (2003), "La sociedad civil y la construcción de ciudadanía". Consultoría Institucional, Universidad Nacional de Córdoba, Argentina

En http://www.consultoriainstitucional. $8 \mathrm{~m} . \mathrm{com} / \mathrm{CIUDADANIA1.htm}$, 6.06.2003.

Arato, Andrew y Cohen, Jean (1999), "La sociedad civil y la teoría social". En Alberto J. Olvera (coord.) La sociedad civil, de la teoría a la realidad. México: Colmex, pp. 83-112.

Von Beyme, Klaus (1994), Teoría política del siglo XX. De la modernidad a la postmodernidad. Madrid: Alianza Editorial.

Dahrendorf, Ralf (1997), "La naturaleza cambiante de la ciudadanía". En La Política. Revista de estudios sobre el Estado y la sociedad. Barcelona: Paidós, Octubre, pp. 139-149.

Davidson, Alastair (2000), "Democracy, Class and Citizenship in a Globalising World". En Andrew Vandenberg (ed.) Citizenship and democracy in a global era. New York St. Martin, pp. 110-120.

Habermas, Jürgen (1998), "Sobre el papel de la sociedad civil y de la opinión pública política", En Facticidad y validez, Madrid: Trotta, pp. 407-468.

Habermas, Jürgen (1996), "El espacio público”. En Nexos, 224 (agosto) (versión electrónica).

Held, David (1997), "Ciudadanía y autonomía". En La Política. Revista de estudios sobre el Estado y la sociedad. Barcelona: Paidós, Octubre, pp. 41-67.

Isin, Engin F. y Turner, Bryan S. (2002), "Citizenship Studies: An Introduction". En Isin, Engin F. y Bryan S. Turner (ed.) Handbook of Citizenship Studies. Londrés: SAGE Publications, pp. 1-10.
Janoski, Thomas y Gran, Brian (2002), "Political Citizenship: Foundations of Rights". En Isin, Engin F. y Bryan S. Turner (ed.) Handbook of Citizenship Studies. Londres: SAGE Publications pp. 13-52.

Kymlicka, Will y Wayne, Norman (1997), "El retorno del ciudadano. Una revisión de la producción reciente en teoría de la ciudadanía". La Política. Revista de estudios sobre el Estado y la sociedad. Barcelona: Paidós, Octubre, pp. 5-39.

Lehning, Percy (1997), "Pluralism, contractarianism and European Union". En Lehning, Percy B. y Albert Weale (eds.) Citizenship, democracy, and justice in the new Europe. London: Routledge, pp. 107-124.

Marx, Anthony (2002), "The nation-state and its exclusions". Political Science Quarterly, New York, vol. 117, núm. 1, pp. 103-126.

Miller, David (1997), "Ciudadanía y pluralismo". En La Política. Revista de estudios sobre el Estado y la sociedad. Barcelona: Paidós, Octubre, pp. 69-92.

Opazo Marmentini, Juan Enrique (2000), "Ciudadanía y democracia. La mirada de las ciencias sociales". En Metapolítica 4,15 , pp. 52-79.

Phillips, Anne (1993), Democracy and difference. The Pennsylvania State University Press, University Park, Pennsylvania.

Shuck, Peter (2002), "Liberal Citizenship". En Isin, Engin F. y Bryan S. Turner (ed.) Handbook of Citizenship Studies. Londres: SAGE Publications, pp. 131-144.

Sojo, Carlos (2002), "La noción de ciudadanía en el debate latinoamericano" Revista de la Cepal, 76, pp. 25-38.

Soltan, Karol Edward (1999), "Introduction: Civic Competence, Democracy, and the Good Society". En Stephen L. Elkin y Karol Edward Soltan (ed.) Citizen 
competence and democratic institutions. University Park, Pa. Pennsylvania State University, pp. 1-13.

Tarrow, Sidney (1998), Power in Movement. Social Movements and Contentious Politics. Cambridge: Cambridge University Press.

Touraine, Alain (1999), ¿Qué es la democracia? Buenos Aires: Fondo de Cultura Económica.

Walter, Michael (1995), "The Civil Society Argument”, En Ronald Beiner (ed.) Theorizing Citizenship. State University of New York Press, Albany, pp. 153-174.

Walter, Michael (1970), Obligations. Essays on Disobedience, War, and Citizenship. Cambridge, Massachusetts: Harvard University Press.
Young, Iris Marion (1995), "Polity and Group Difference: A Critique of the Ideal of Universal Citizenship". En Ronald Beiner (ed.). Theorizing Citizenship. State University of New York Press, Albany, pp. 175-207.

Zapata-Barrero, Ricard (2001), Ciudadanía, democracia y pluralismo cultural: hacia un nuevo contrato social. Anthropos, Barcelona.

Zolo, Danilo (1997), "La ciudadanía en una era poscomunista". En La Política. Revista de estudios sobre el Estado y la sociedad. Barcelona: Paidós, Octubre, pp. 117-131. 